\title{
Observations of the Small-Scale Variability of Precipitation Using an Imaging Radar
}

\author{
RoBerT D. PALMER \\ School of Meteorology, University of Oklahoma, Norman, Oklahoma \\ Boon Leng Cheong and Michael W. Hoffman \\ Department of Electrical Engineering, University of Nebraska at Lincoln, Lincoln, Nebraska \\ STEPHEN J. Frasier AND F. J. LÓPEZ-DeKKer \\ Department of Electrical and Computer Engineering, University of Massachusetts-Amherst, Amherst, Massachusetts
}

(Manuscript received 16 September 2004, in final form 11 February 2005)

\begin{abstract}
For many years, spatial and temporal inhomogeneities in precipitation fields have been studied using scanning radars, cloud radars, and disdrometers, for example. Each measurement technique has its own advantages and disadvantages. Conventional profiling radars point vertically and collect data while the atmosphere advects across the field of view. Invoking Taylor's frozen turbulence hypothesis, it is possible to construct time-history data, which are used to study the structure and dynamics of the atmosphere. In the present work, coherent radar imaging is used to estimate the true three-dimensional structure of the atmosphere within the field of view of the radar. The 915-MHz turbulent eddy profiler radar is well suited for imaging studies and was used in June 2003 to investigate the effects of turbulence on the formation of rain. The Capon adaptive algorithm was implemented for imaging and clutter rejection purposes. In the past several years, work by the authors and others has proven the Capon method to be effective in this regard and to possess minimal computational burden. A simple but robust filtering procedure is presented whereby echoes from precipitation and clear-air turbulence can be separated, facilitating the study of their interaction. By exploiting the three-dimensional views provided by this imaging radar, it is shown that boundary layer turbulence can have either a constructive or destructive effect on the formation of precipitation. Evidence is also provided that shows that this effect can be enhanced by updrafts in the wind field.
\end{abstract}

\section{Introduction}

Modern atmospheric radars are typically operated in the VHF band for observations of the structure and dynamics of clear-air turbulence from the troposphere to the mesosphere (Woodman and Guillen 1974). These radars often have large apertures $(50-100 \mathrm{~m})$ with corresponding beamwidths of $3^{\circ}-6^{\circ}$. Also known as mesosphere-stratosphere-troposphere (MST) radar, such research systems have been used successfully for decades for measurements of wind and reflectivity fields. Systems operating close to $400 \mathrm{MHz}$ have been designed for operational use and are deployed across

Corresponding author address: Robert D. Palmer, Dept. of Meteorology, University of Oklahoma, 100 E. Boyd, Room 1310, Norman, OK 73019.

E-mail: rpalmer@ou.edu the central region of North America (Weber et al. 1990). For studies of the atmospheric boundary layer (ABL), shorter-wavelength radars, of a similar design, are used and are commercially available. These boundary layer radars (BLRs) operate near $1 \mathrm{GHz}$ and are capable of observations from near $100 \mathrm{~m}$ to a few kilometers in altitude, depending on the atmospheric conditions (Ecklund et al. 1988).

Originally developed for observations of the ionosphere (Pfister 1971; Woodman 1971), spatial interferometry (SI) has proven to be very useful for highresolution localization of coherent structures (e.g., Farley et al. 1981; Kudeki et al. 1981; Röttger and Ierkic 1985). Spatial interferometry is based on the use of interference patterns in coherent signals received from spatially separated antennas. Many factors can affect the interference pattern, including the wind field and the structure of the scatterers. It has also been shown 
that the size distribution of precipitation particles can affect the SI method (Chilson et al. 1995). Of course, it is just these effects that are used to study the physics of the atmosphere.

By coherently summing signals from an interferometric radar system, rudimentary beam forming (imaging) is possible. These simple methods, based on the spatial Fourier transform, were termed postset beam steering (Röttger and Ierkic 1985) and poststatistic steering (Kudeki and Woodman 1990; Palmer et al. 1993). The first true imaging experiments using several spatially separated receive elements were conducted by Kudeki and Sürücü (1991) for observations of the equatorial electrojet. The term coherent radar imaging (CRI) was coined for this beam-forming process. The maximum entropy method was later employed to enhance angular resolution (Hysell 1996). Subsequently, Palmer et al. (1998) used the data-dependent algorithm based on the work of Capon (1969) for observations of clear-air turbulence and precipitation using the Middle and Upper (MU) Atmosphere radar. More recently, this method has been used to study the dynamics of coherent echoes from the polar mesosphere (Yu et al. 2001). Given the numerous algorithms available for CRI applications, statistical investigations have been undertaken to determine the advantages and disadvantages of each technique (e.g., Yu et al. 2000; Chau and Woodman 2001). An attempt to generalize the theory of radar imaging has been made by Woodman (1997). For a review of the relevant literature, see Luce et al. (2001).

Given the increasing need for higher-resolution measurements, new or upgraded systems have been developed to exploit the potential of imaging. For example, a French radar has been recently modified to allow the implementation of imaging methods (Hélal et al. 2001). The MU radar, which has been used successfully for many years (Fukao et al. 1985a,b), has also undergone a significant upgrade to 25 independent receivers. For applications to tropical meteorology, plans are also underway that would facilitate the implementation of imaging on the Indian MST radar (Rao et al. 1995; Jain et al. 1995). As mentioned earlier, radar observations of the ABL are typically conducted using frequencies close to $1 \mathrm{GHz}$. With the goal of real-time mapping the three-dimensional turbulent field of the ABL, the turbulent eddy profiler (TEP) was developed by researchers at the University of Massachusetts (Mead et al. 1998). This $915-\mathrm{MHz}$ BLR has up to 64 independent receivers, allowing the use of sophisticated imaging algorithms with unprecedented flexibility. The system is capable of mapping a conical volume above the radar limited by the beamwidth of the transmit antenna. TEP has been used for observations of the convective boundary layer (CBL), which compared favorably to numerical simulations (Pollard et al. 2000). In conjunction with a radio acoustic sounding system, the TEP radar was used to study the propagation and distortion of acoustic waves (Lopez-Dekker and Frasier 2004). The goal of the present work is to show the usefulness of the TEP radar for small-scale studies of precipitation.

Precipitation is often characterized by the drop size distribution (DSD), which is in turn used to quantify rainfall rate, for example. Using scanning weather radar, studies have been conducted to investigate the spatial and temporal variability of rainfall rate (Crane 1990). However, the spatial resolution was on the order of kilometers. In a series of papers, Jameson et al. (1999, and references therein) have brought into question assumptions concerning the homogeneity of precipitation. Recently, observations of convective precipitation have shown the Doppler sorting effect caused by updrafts (Kollias et al. 2001). In addition, the interaction of cloud particles and turbulence has been reviewed by Vaillancourt and Yau (2000). Previous work using a 915-MHz BLR has shown the effect that light rain can have on the reflectivity of turbulent layers (Cohn et al. 1995). Here, we present data from the TEP radar that show the significant influence of turbulence on the formation of precipitation. It is further shown that the mean vertical wind can enhance this effect. Three-dimensional images of precipitation and clear-air turbulence echoes are provided, exemplifying the interplay of these distinct atmospheric phenomena.

In the next section, the experimental configuration using TEP is presented. Then, the meteorological conditions during the experiment are analyzed. Finally, results from both standard processing and imaging are given in an attempt to understand the effects of $\mathrm{ABL}$ turbulence on the precipitation that occurred during the experiment.

\section{Experimental configuration using the turbulent eddy profiler}

An extensive experiment was conducted in Amherst, Massachusetts, in June 2003 using the TEP radar with the goal of assessing the capabilities of the system for observing a variety of boundary layer phenomena. Just prior to the observations, a cold front had pushed off the southeastern coast of the United States with a weak low pressure system off the Massachusetts coast. An upper-level low was located just south of the surface low, resulting in counterclockwise winds flowing around the cyclone. This wind, along with the cold air mass present to the southwest of Massachusetts, caused 
overrunning of warm air and sporadic light rain during the experiment.

In its current configuration, the 915-MHz TEP radar consists of a transmit horn antenna and a receive array of up to 64 microstrip patch elements separated by approximately $0.57 \mathrm{~m}$ (Mead et al. 1998; Lopez-Dekker and Frasier 2004). The exact number of elements is dependent upon the array configuration used. Signals from each receive element are sent through a low-noise amplifier before being fed to the control trailer. These signals are input to individual analog receivers and coherently integrated on specially designed integratedcircuit boards, each with four receivers. The coherently integrated in-phase and quadrature signals are then stored to disk for further processing. By coherently combining the signals from the individual elements, it is possible to image the atmosphere in a cone-shaped volume above the radar. A depiction of the TEP imaging concept is provided in Fig. 1. The transmit beamwidth of TEP is shown as the relatively wide angular region that defines the field of view of the radar. Imaging consists of combining the individual receiver signals in order to synthesize narrow focused beams within the transmit beam. By adjusting the method by which the signals are combined, it is possible to create a map, or image, of the atmosphere above the radar. This process is conducted for each range gate individually, resulting in a three-dimensional image. Given the inherent flexibility designed into the TEP array, it is also possible to investigate advantages of various array configurations and processing schemes. Data from one of these configurations are discussed here in the context of the spatial variability of precipitation on scales less than the overall size of the TEP volume, which has a maximum horizontal dimension of approximately $1 \mathrm{~km}$.

In an attempt to achieve the highest possible angular resolution with the TEP array, the so-called $\mathrm{Big}-\mathrm{Y}$ configuration was designed. The schematic of the array layout and a photograph of the system are provided in Fig. 2. With a similar design to the Very Large Array in New Mexico, the Big-Y TEP configuration was achieved by building three outrigger arms and placing seven array elements on each. The center portion of the array keeps with the original hexagonal lattice design of the TEP system (Mead et al. 1998) but with only 37 elements. This sparse array can obtain the angular resolution expected from a filled array with an aperture of $11.3 \mathrm{~m}$ but at the expense of increased sidelobe levels and smaller gain. However, adaptive array processing schemes can be used to mitigate the adverse effects of the sidelobes.

Accurate phase calibration is essential for obtaining useful images from any phased array radar, and the

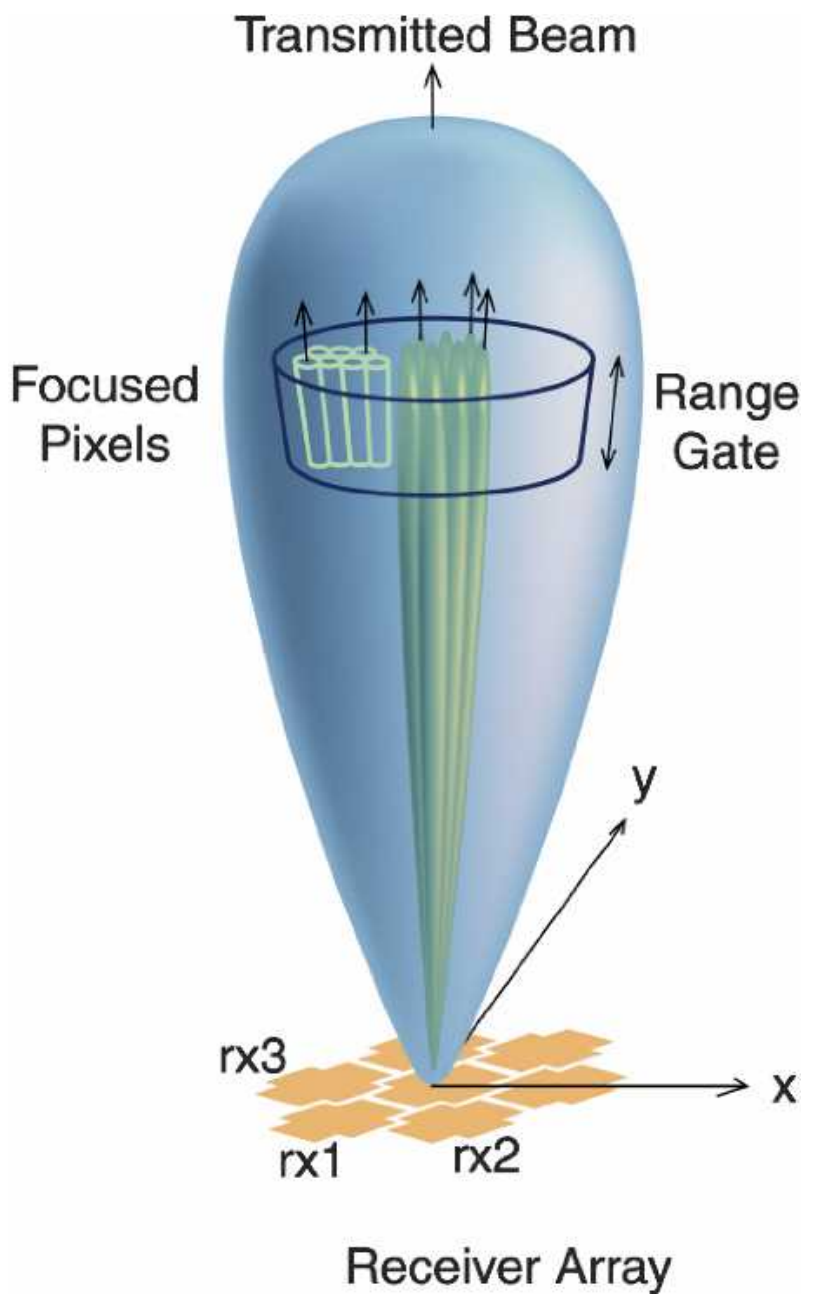

FIG. 1. An artist's depiction of the TEP radar and general imaging process. The transmit beam is shown as the relatively wide angular region. By beam forming, or imaging, it is possible to combine the signals from the individual receivers into a set of narrow beams within the transmit beam. Note that the actual TEP array consists of many more receivers than are shown.

TEP system in particular. As mentioned, the flexibility of the placement of the array elements has many advantages. However, phase calibration can become problematic for sparse arrays when segments of the array are separated by several wavelengths, as is the case with the Big-Y configuration. At present, successful calibration has been accomplished for only the center segment of the Big-Y array, which has an aperture of approximately $3.4 \mathrm{~m}$. Therefore, the results presented will be limited to data from this portion of the array. An angular resolution of approximately $5.4^{\circ}$ is achieved with this subarray using Fourier-based array processing schemes. However, high-resolution algorithms will be exploited to improve the resolution to approximately 2.7 (e.g., Yu et al. 2000). As mentioned, the TEP radar 

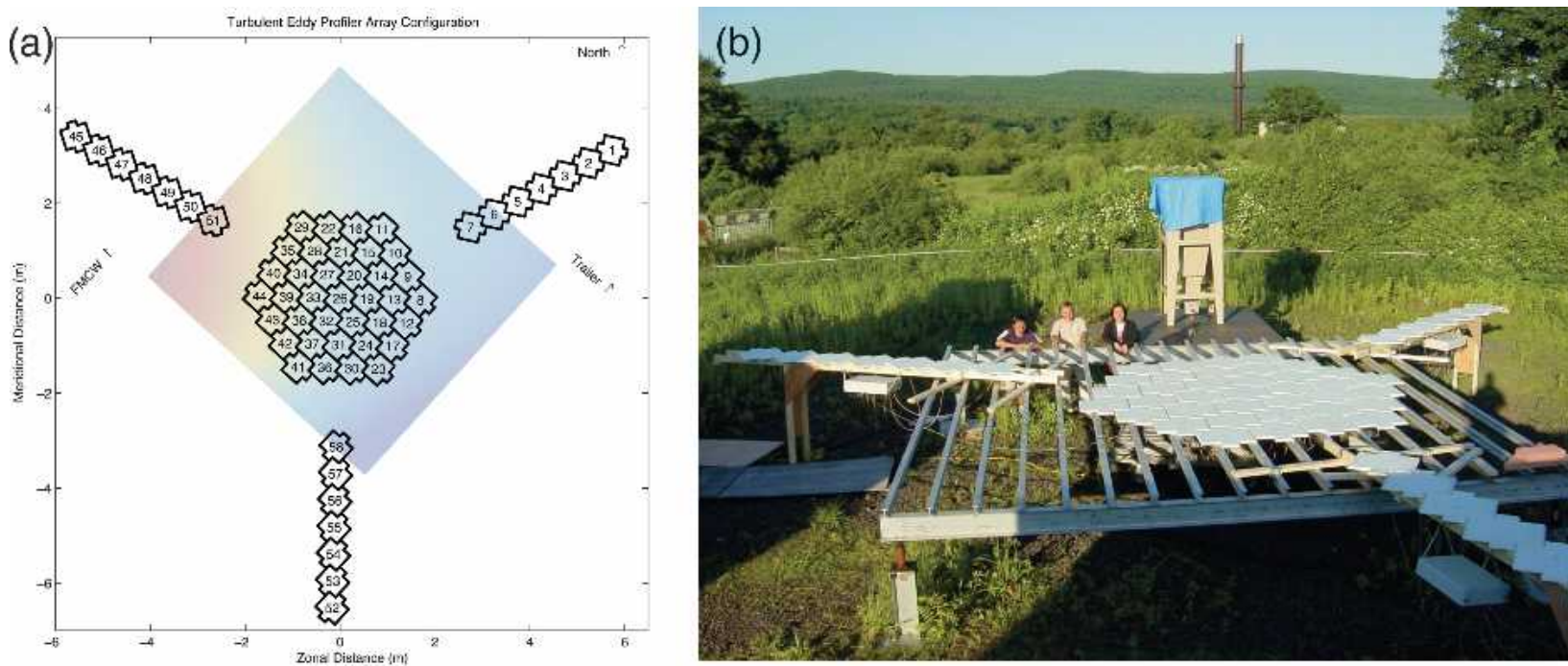

FIG. 2. (a) TEP receive array configuration along with a photograph from the experiment. Shading on the array schematic provides precise measurements of the element heights, which are essential for phase calibration. The overall aperture of this sparse array approaches $11.3 \mathrm{~m}$. (b) The photograph shows the array with the transmit horn antenna in the background.

was originally designed to incorporate a separate transmit antenna, which can be seen in the background of the photograph of Fig. 2. As a result, no high-speed T/R switch was necessary, and observations close to the surface were facilitated. The current transmit horn antenna has a $25^{\circ}$ one-way, half-power, beamwidth that defines the imaged volume. At an altitude of $2 \mathrm{~km}$, the volume has a coverage width of approximately $887 \mathrm{~m}$. The peak transmit power was $4 \mathrm{~kW}$.

The pulse repetition frequency (PRF) was set to 35 $\mathrm{kHz}$ with 250 coherent integrations, resulting in an effective sampling time of $7.14 \mathrm{~ms}$. Given the operating frequency of $915 \mathrm{MHz}$, the aliasing velocity for the experiment was $11.48 \mathrm{~m} \mathrm{~s}^{-1}$, which was adequate for the maximum radial velocities expected in the boundary layer. Data blocks consisting of 260 time series points from all receivers were recorded every $2.5 \mathrm{~s}$, including overhead for storage and online processing. Most of the results to be presented were obtained using two incoherent integrations, resulting in an approximate 5-s temporal resolution. A pulse width of $222 \mathrm{~ns}$ was used, providing $33.3-\mathrm{m}$ range resolution. At a nominal altitude of $1 \mathrm{~km}$ and given the expected angular resolution of $2.7^{\circ}$, the TEP configuration used for the present experiment was capable of observations of approximately $47 \mathrm{~m} \times 47 \mathrm{~m} \times 33 \mathrm{~m}$ subvolumes within the overall volume defined by the transmit beam. Sixty-four (64) range gates were sampled from just before the transmit pulse was launched to a maximum time corresponding to an altitude of $1.93 \mathrm{~km}$. Of course, the gates sampled before the transmit beam are not useful. Further, ground clutter limited the lowest observable altitude to approximately $100 \mathrm{~m}$ using our adaptive clutter rejection algorithms (Palmer et al. 1998).

With the given sampling rate and the numerous receivers of the TEP radar, it was difficult to continuously record data for periods longer than several hours. The data presented here were taken on 21 June 2003, over the 3-h period 1805-2105 UTC. Although transportable, the TEP radar was used while deployed at the experimental home facility operated by the University of Massachusetts, Amherst $\left(42.38^{\circ} \mathrm{N}, 72.52^{\circ} \mathrm{W}\right)$.

\section{Experimental results}

Raw in-phase and quadrature data from this experiment were processed offline in order to generate threedimensional images of echo power and radial velocity within the field of view of the radar $\left( \pm 12.5^{\circ}\right)$. The complex time series data from each of the 37 receivers were combined using previously developed imaging methods based on data-adaptive concepts (Palmer et al. 1998). Let the time-domain signals from the 37 receivers be combined into the data vector denoted by $\mathbf{x}(t)$. The imaging process is accomplished by linearly combining the 37 signals by the following simple vector multiplication,

$$
y(t)=\mathbf{w}^{\dagger} \mathbf{x}(t),
$$

where the dagger represents the Hermitian operator (conjugate transpose). The scalar time-domain signal $y(t)$ corresponds to the angular position within the field of view determined by the complex weighting vector $\mathbf{w}$, which is a function of the desired zenith and azimuth 

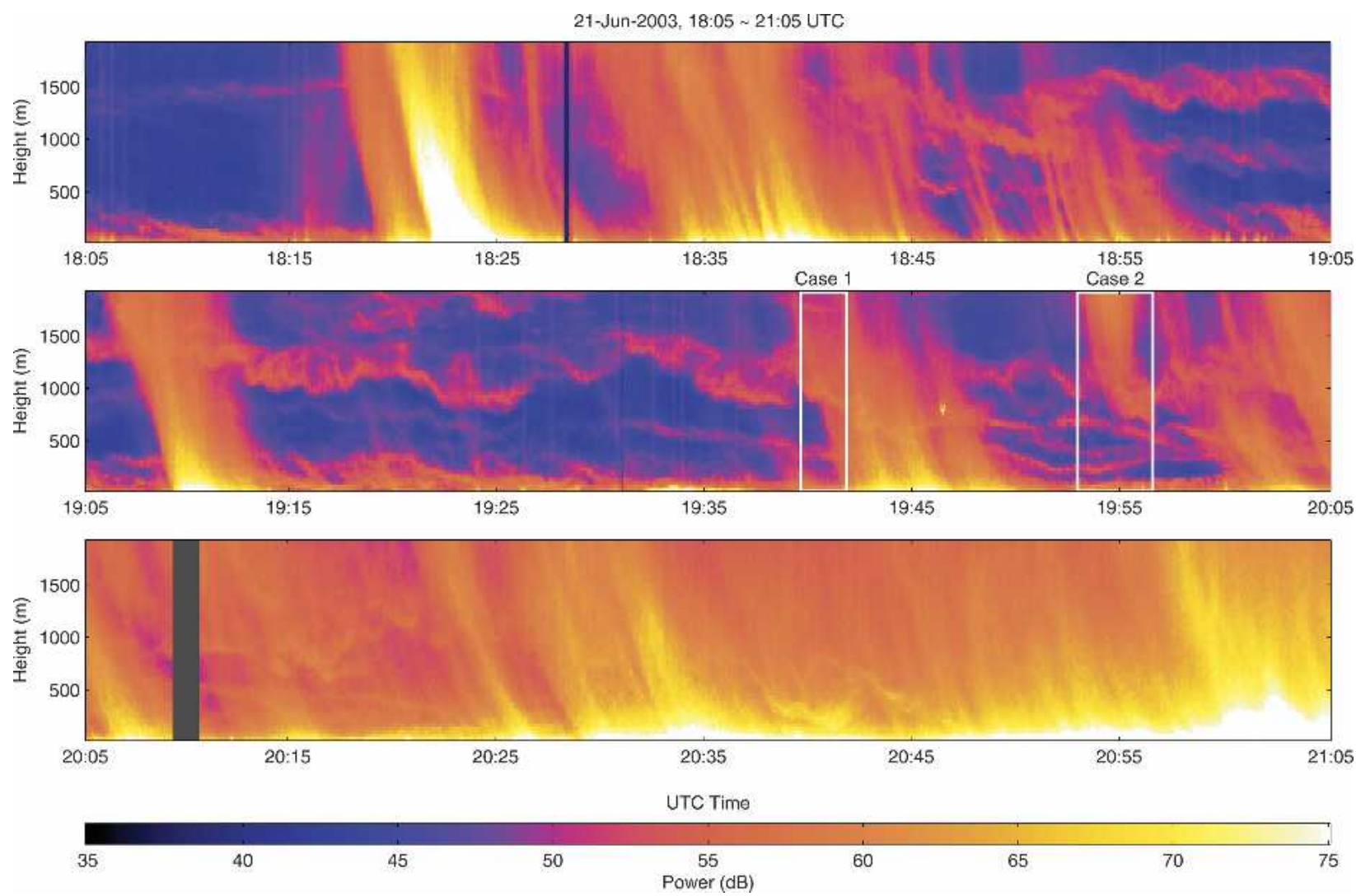

FIG. 3. Time history of echo power during 1805-2105 UTC 21 Jun 2003. During the observation time, sporadic precipitation occurred along with several turbulent layers. During much of experiment, both clear-air and precipitation echoes could be observed in the data. However, the later portion of the data is dominated by strong precipitation echoes. Two specific case studies are outlined.

angles. By adjusting $\mathbf{w}$ to scan through the field of view, the resulting set of $y(t)$ signals can be used to estimate maps of Doppler spectra, or simply echo power and radial velocity, using standard algorithms (Cheong et al. 2004). Of course, this process is typically carried out for each range gate individually and therefore provides a three-dimensional view of the atmosphere above the radar.

To achieve high angular resolution and mitigate the effects of both ground and biological clutter, the adaptive Capon method (Capon 1969) was chosen for generation of the weighting vector w. Many other algorithms have been developed for the imaging process (e.g., Haykin 1985; Kudeki and Sürücü 1991; Hysell 1996) but the authors have found the Capon method to provide good resolution with only moderate computational complexity (Yu et al. 2000). For a complete derivation of the Capon weighting vector for the atmospheric imaging case, see Palmer et al. (1998). For the present study, it is sufficient to say that the complex weighting vector $\mathbf{w}$ is data dependent and is systematically adjusted for each solid angle within the field of view of the radar, as shown in Fig. 1.

\section{a. Echo power and vertical motion}

After proper phase and amplitude calibration, the weight vector was designed to produce a narrow vertical beam. The signal from that beam was used to produce estimates of echo power and radial (vertical) velocity using the so-called pulse pair beam former (PPB) (Cheong et al. 2004). The echo power results over the 3-h extent of the observations are provided in Fig. 3. Note that two distinct time periods (cases 1 and 2) are outlined in the figure for emphasis and are discussed in more detail in coming sections. The most striking features are the precipitation streaks mixed with clear-air turbulent layers. Although often masked by the relatively strong precipitation echoes, the turbulent layers often show patterns indicative of Kelvin-Helmholtz instabilities (Gossard 1990). For example, a classic braided pattern is observed from 1855 to 1905 UTC at an altitude of approximately $1.5 \mathrm{~km}$. The tilting effect of the precipitation echoes could be caused by the descent of precipitation toward the surface. However, the horizontal structure of the precipitation cannot be determined from these rather routine observations. Later 

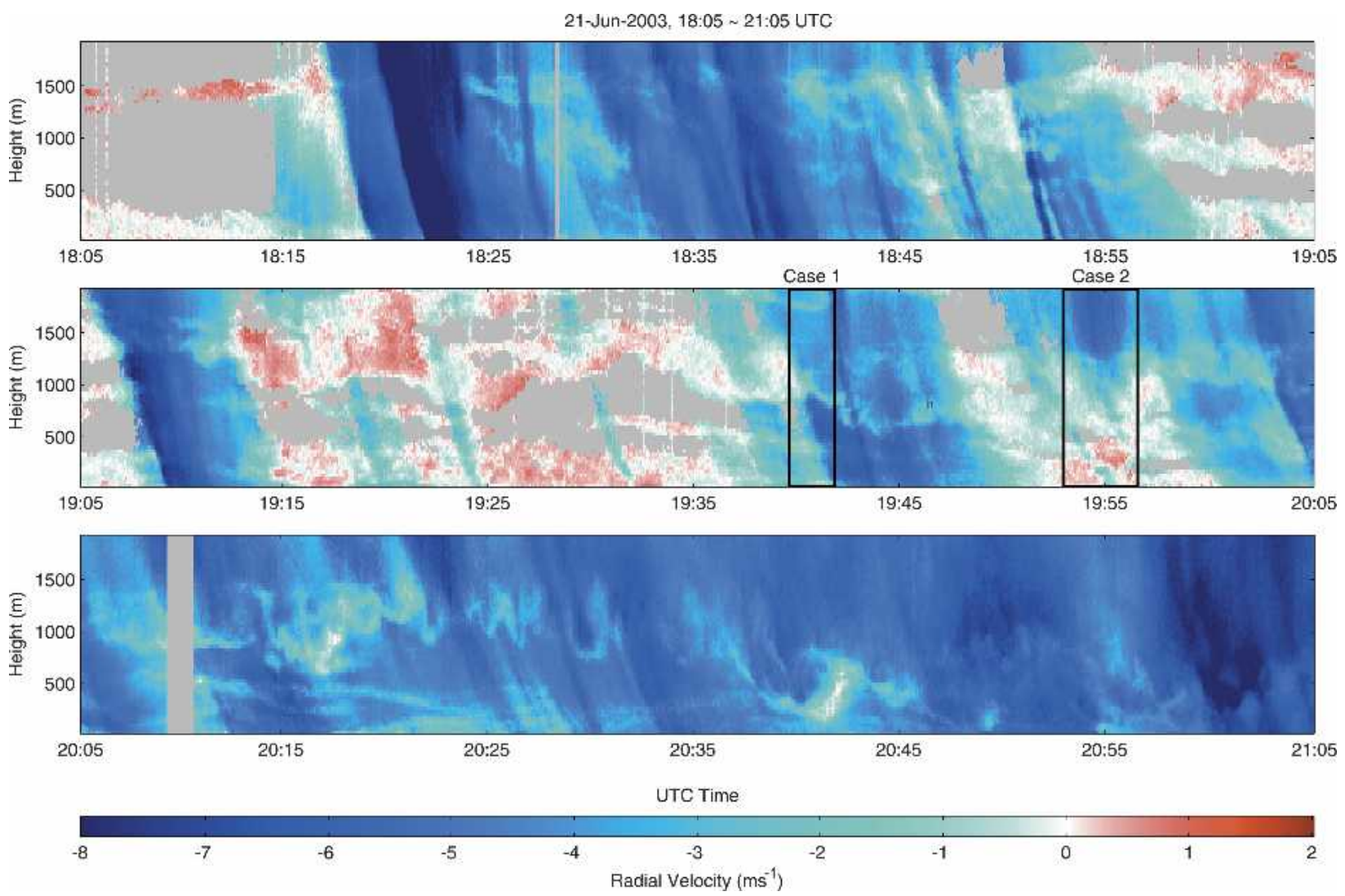

FIG. 4. Same as previous figure, except for vertical velocity. Note that the color scale is centered around large negative velocities to emphasize the precipitation.

sections deal with horizontal structure through the use of imaging. For now, it is assumed that the echoes are caused by sporadic precipitation. The fall speed can be estimated by the apparent tilt of the rain streaks in the echo power time-history plot. For example, the rain streaks occurring at 1835 UTC descend from the top of the observation range $(1.93 \mathrm{~km})$ to the surface in approximately $4 \mathrm{~min}$, which corresponds to an $8 \mathrm{~m} \mathrm{~s}^{-1}$ fall velocity. Assuming no vertical wind, a terminal fall velocity of this magnitude could result from drops with diameters close to $3 \mathrm{~mm}$ (Gunn and Kinzler 1949).

Another interesting feature observed is the interaction between the turbulent layers and the precipitation. Work by Cohn et al. (1995) has shown that rain can affect the reflectivity measured by radar. It is also known that turbulent flow can have a significant effect on both the spatial and velocity distributions of cloud droplets (Vaillancourt and Yau 2000). Further, rain can exhibit clustering caused by small-scale turbulence due to its effect on collisions and the resulting coalescence or breakup (Pruppacher and Klett 1997; Jameson et al. 1999). Contrasting examples of the interaction of rain with turbulent layers can be observed at 1944 and 1955
UTC. At 1944 UTC, relatively weak precipitation is seen in the upper ranges. After passing through the turbulent layer at an altitude of approximately $800 \mathrm{~m}$, the intensity of the echo increases significantly, indicating significant coalescence. In contrast, the precipitation echo at 1955 UTC appears at the upper altitudes but is then dissipated just below the turbulent layer at approximately $1000 \mathrm{~m}$. The exact cause could be related to evaporation or breakup. Nevertheless, the correlation between the location of dissipation and the turbulent layer is unmistakable. Using imaging, the threedimensional spatial structure of these events is studied in more detail in later sections.

The time history of the vertical velocity is provided in Fig. 4. The color scale was chosen so that negative (downward) velocities are shaded in blue, zero is white, and red tints are positive (upward). The mixture of the falling precipitation and oscillating clear-air turbulence makes the data difficult to interpret. Nevertheless, the tilted rain echoes are seen to have vertical velocities from -8 to $-2 \mathrm{~m} \mathrm{~s}^{-1}$. The velocities corresponding to clear-air echoes are seen to oscillate with periods on the order of minutes. 


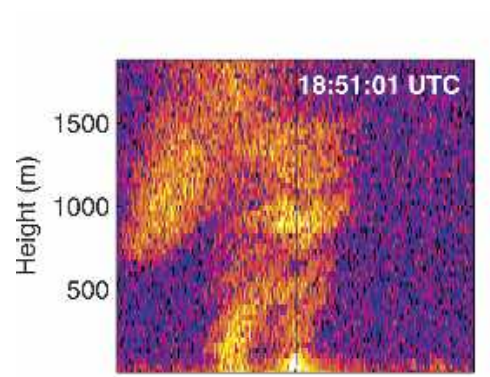

Dataset on 21-Jun-2003: Time Spectra of Receiver \#23
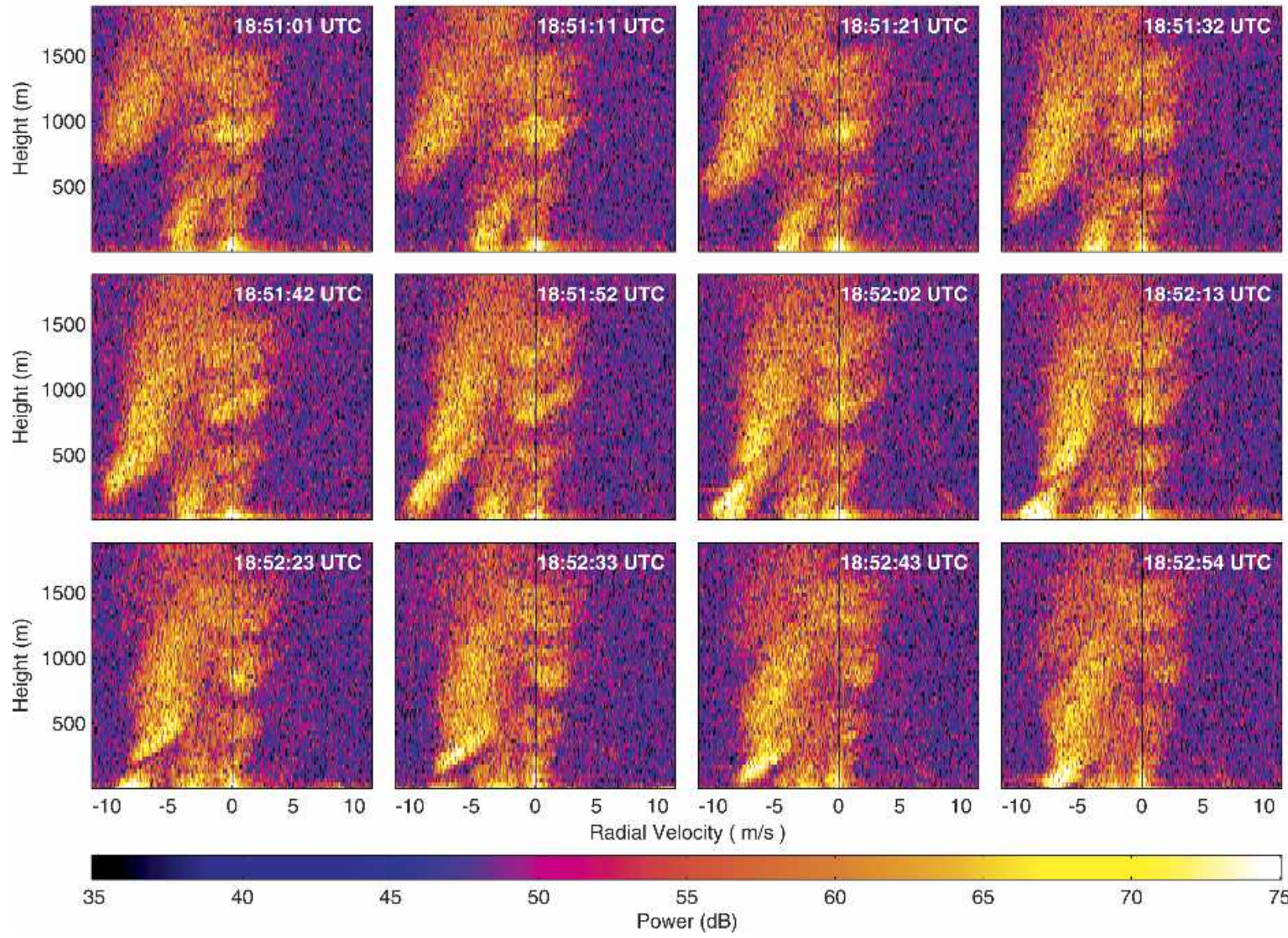

FIG. 5. Time sequence of Doppler spectra for a 2-min period (1851:01-1852:54 UTC). A layer of precipitation can initially be seen at an altitude of approximately $1 \mathrm{~km}$ and progresses to the surface with time. Note the simultaneous clear-air echoes with radial velocities less than $\pm 2 \mathrm{~m} \mathrm{~s}^{-1}$.

The 33-cm wavelength of the TEP radar allows the simultaneous observation of Bragg-scale turbulence and precipitation, which causes Rayleigh scatter. Of course, this can make interpretation rather problematic. In the next section, it is shown how frequency selectivity can be used with imaging to separate these distinct echoes, facilitating their study.

\section{b. Feature separation using frequency-selective imaging}

Under certain conditions, Doppler spectra from vertically pointing radar can exhibit two peaks-one due to clear-air turbulence and the other to precipitation (Wakasugi et al. 1986). A sequence of just such spectra is shown in Fig. 5 for 12 frames from 1851:01 to 1852:54 UTC. In the first frame, a precipitation echo is observed at an altitude of approximately $1 \mathrm{~km}$ with an apparent fall speed close to $-8 \mathrm{~m} \mathrm{~s}^{-1}$. As time progresses through the 12 frames, the layer is seen to fall toward the surface. During the entire event, obvious clear-air echoes are seen throughout the observation range. These echoes can be discriminated from the precipitation echoes by their relatively small vertical velocities. Typical clear-air vertical velocities in a nonconvective environment will rarely exceed $\pm 2 \mathrm{~m} \mathrm{~s}^{-1}$.

Using a similar technique to Palmer et al. (1998), it is possible to exploit the distinct vertical velocity characteristics of clear-air turbulence and precipitation to separate the two processes. This is accomplished by passing the individual receiver signals through temporal filters before the imaging process. The precipitation signal was extracted by passing the 37 receivers' time series signals through an eighth-order, high-pass, elliptical filter (HPF). A cutoff velocity of $\pm 2 \mathrm{~m} \mathrm{~s}^{-1}$ was chosen, virtually eliminating the clear-air echo. Output signals 

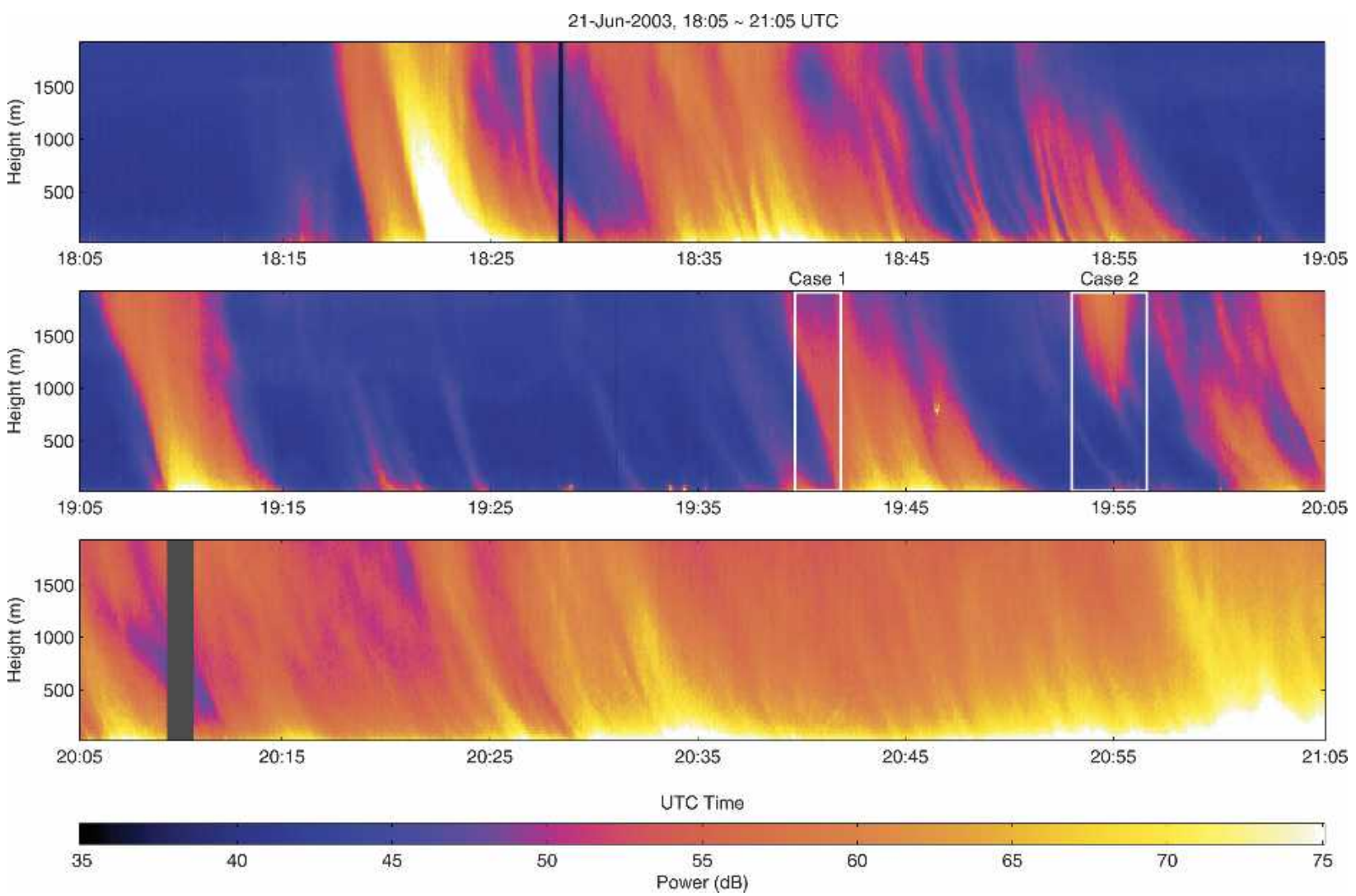

FIG. 6. Time history of synthesized precipitation echo power. These data were obtained by high-pass filtering before the imaging process, which isolates the precipitation echo from the clear-air turbulent echo.

were then used for the imaging process in the same manner as that used to produce Fig. 3. The synthesized precipitation echo power, free from clear-air contamination, is shown in Fig. 6. Due to the non-ideal HPF filter, some residual clear-air signal is present in the data. Nevertheless, many features not obvious before filtering are now prominent and are discussed in more detail in the next section.

A significant advantage is realized when the complementary filtering process is implemented by passing the 37 time series signals through a low-pass filter (LPF) of a design similar to that of the HPF. Again, the cutoff velocity was set to $\pm 2 \mathrm{~m} \mathrm{~s}^{-1}$, but the filter was designed to attenuate the precipitation echo. However, by temporally filtering before imaging, the input-filtered signal originates from a wider angular region than would have been the case if imaging had been performed first. At large off-vertical angles, the geometric projection (radial velocity) of the fall speed of the precipitation may be small enough to allow a precipitation signal to pass through the filter. Although much more cumbersome and computationally expensive, imaging before temporal filtering would mitigate this possible artifact. Nev- ertheless, given the $\pm 12.5^{\circ}$ transmit beamwidth, this filter leakage effect should be small. The resulting synthesized clear-air echo power is provided in Fig. 7. Note how the filtering/imaging process reveals coherent structure in the time history that was completely masked by precipitation in Fig. 3. In particular, the lower panel of the figure (2005-2105 UTC) shows a braided structure at an altitude of 100-500 $\mathrm{m}$ for 20052025 UTC. It would have been impossible to study these echoes without the use of the LPF and imaging.

There are two well-known, radar-based methods of estimating turbulent intensity. The first uses the radar reflectivity $(\eta)$ of turbulence within the resolution volume to estimate the structure function parameter of refractivity $C_{n}^{2}$, which is a measure of turbulent intensity. Tatarskii (1961) showed the following formulation:

$$
\eta=0.38 C_{n}^{2} \lambda^{-1 / 3}
$$

where $\lambda$ is the radar wavelength. It is assumed that turbulence exists and is isotropic and in the inertial subrange. Further, the radar resolution volume is assumed to be uniformly filled with turbulence. Given the 

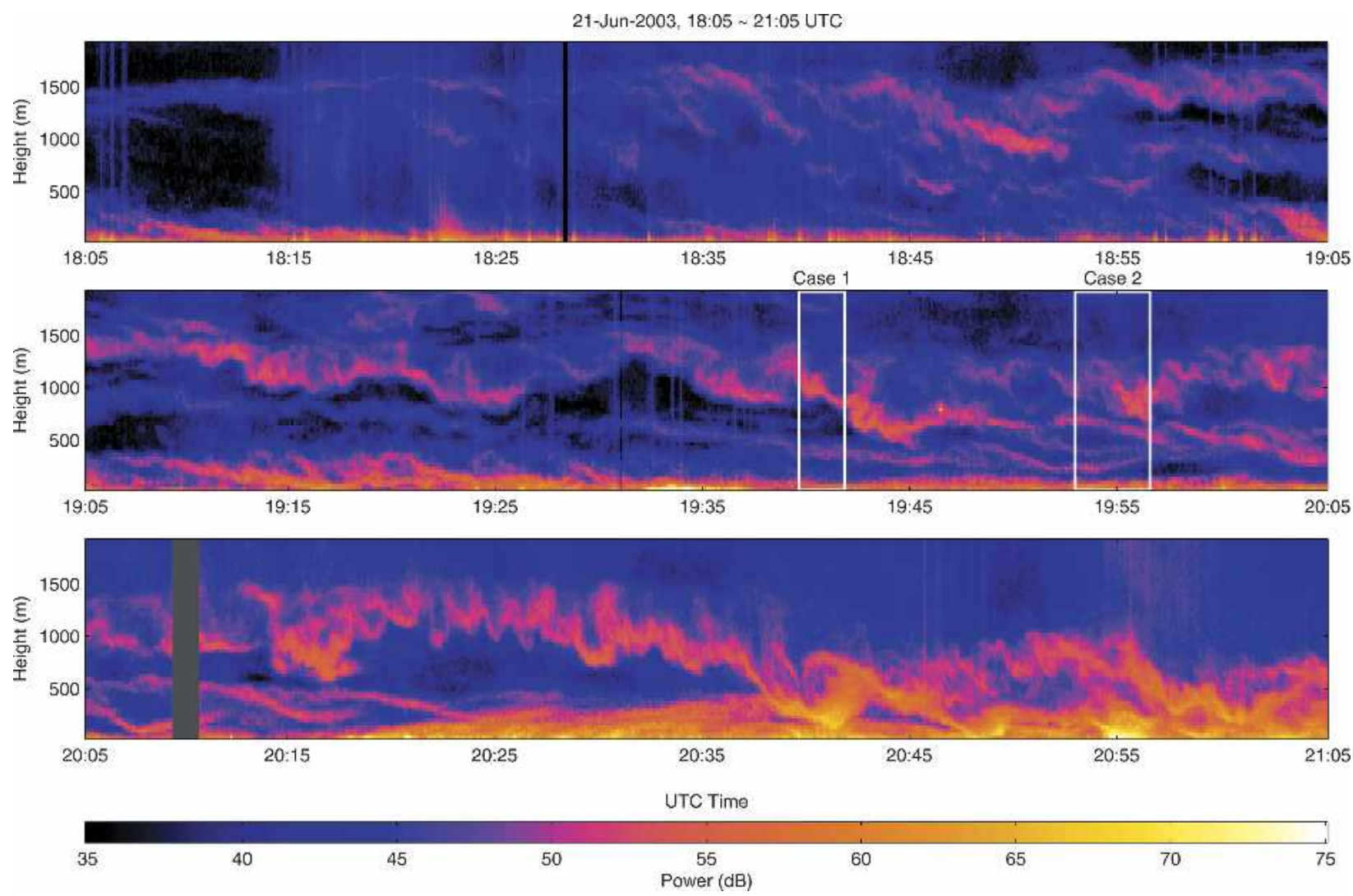

FIG. 7. Time history of synthesized clear-air echo power. These data were obtained in a similar manner to those of the previous figure, except using a low-pass filter, which significantly attenuates the precipitation signal.

intermittency of turbulence in the ABL, it is unlikely that a relatively large resolution volume ever fulfills this assumption. With the TEP radar and the use of highresolution algorithms, however, the filled-volume assumption is more valid, since the imaged volumes are much smaller than with standard processing. It should be mentioned that this method of estimating turbulent intensity is dependent upon obtaining estimates of radar reflectivity, which is only possible with a powercalibrated radar. The TEP system is currently not power calibrated, so only the structure and relative intensity of the turbulent eddies can be imaged, as shown in Fig. 3. The second method of estimating turbulent intensity is through the direct measurement of velocity variation within the volume of the radar. It can be shown that the turbulent eddy dissipation rate $(\epsilon)$ is related to the so-called spectrum width $\left(\sigma_{v}^{2}\right)$ by the following equation (Hocking 1986):

$$
\epsilon=0.31 \sigma_{v}^{2} N
$$

where $N$ is the Brunt-Väisälä frequency. The measurement of the spectrum width of the Doppler spectrum has several effects that tend to bias it to larger values.
Given a known beam pattern of the radar, however, it is possible to remove these effects and estimate the velocity variation due to turbulence (Cohn 1995). In the TEP radar case using data-dependent algorithms, the task of bias removal is complicated by the adaptive beam pattern (Cheong et al. 2004). As a result, it is prudent to use the echo power (Fig. 3), in lieu of spectrum width, a measure of relative turbulent intensity.

After filtering, it is also possible to image radial velocity. Vertical velocity (without filtering) was previously shown in Fig. 4 exhibiting a complicated mixture of turbulent and precipitation velocity fields. As such, it was difficult to study the interplay between these two distinct processes. Using the same LPF designed to isolate the clear-air signal, maps of radial velocity were estimated for the field of view of the radar $\left( \pm 12.5^{\circ}\right)$. A $32 \times 32$ grid of pixels over this field of view was used to map the radial velocity. As before, the vertical pixel was used to estimate vertical velocity, and the time history is shown in Fig. 8. In contrast to Fig. 4, a different color scale has been used to enhance the smallermagnitude velocity features. Accepting only those pixels with signal-to-noise ratio (SNR) greater than $3 \mathrm{~dB}$, 

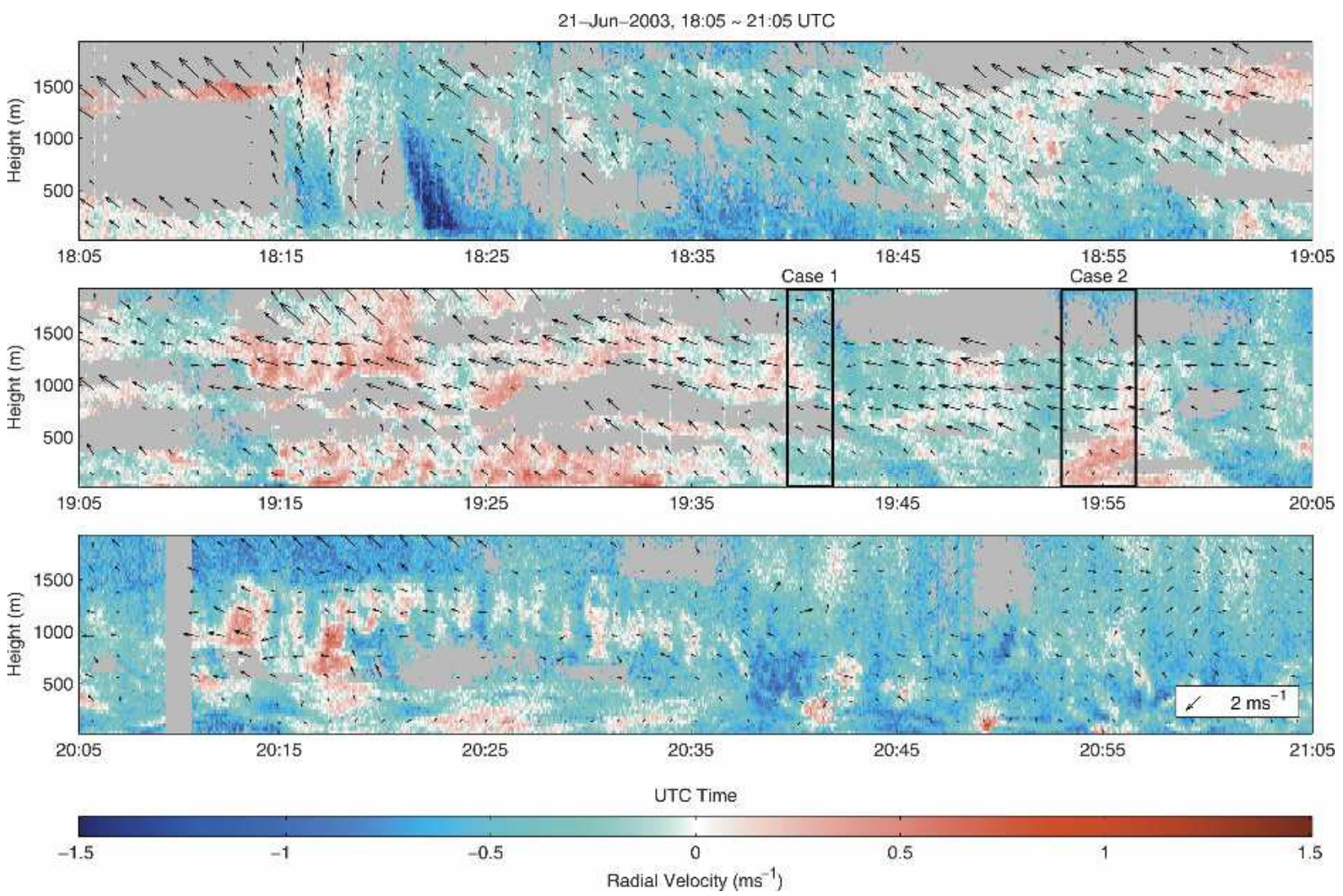

FIG. 8. Time history of synthesized clear-air vertical and horizontal wind vectors. Vertical velocity estimates were obtained from the radial velocity of the imaged vertical pixel. Horizontal wind vectors were estimated using a least squares DBS method, which uses the radial velocity field. Note that both temporal and height averaging has been performed on the horizontal wind vectors. A different color scale has been used from that shown in Fig. 4.

an over determined Doppler beam swinging (DBS) method was implemented in order to estimate the horizontal wind profile that best fits the radial velocity field in a least squares sense. These wind vectors are overlaid on the vertical velocity plot with appropriate averaging in both time and height in order to facilitate interpretation. The arrows point in the direction of motion of the horizontal wind field.

Using the 0000 UTC (22 June 2003) sounding from Albany, New York, and the horizontal wind estimates shown in Fig. 8, it was possible to calculate the bulk Richardson number (Ri). This important indicator of mechanically induced turbulence (dynamic instability) is given by

$$
\mathrm{Ri}=\frac{g \partial \theta_{v} / \partial z}{\bar{\theta}_{v}\left[(\partial u / \partial z)^{2}+(\partial v / \partial z)^{2}\right]},
$$

where $\theta_{v}$ is the virtual potential temperature; $g$ is the acceleration due to gravity; the mean virtual potential temperature is $\bar{\theta}_{v}$; and the zonal and meridional components of the horizontal wind vector are denoted by $u$ and $v$, respectively. Estimated $\mathrm{Ri}$ values are given in Fig. 9 over the entire observational period. Given the coarse height sampling of the sounding data, the buoyancy damping term in (4) was assumed constant and estimated to be close to neutral $\left(0.00432 \mathrm{~K} \mathrm{~m}^{-1}\right)$. Therefore, the shear term dominated our estimate of Ri. Height gradients were calculated over a $200-\mathrm{m}$ region with a 75-s temporal average. Although the data show a relatively high degree of variability, an interesting example is seen at approximately 1816 UTC and at an altitude of $1.2 \mathrm{~km}$. The Ri data show relatively stable conditions $(\mathrm{Ri}>0.25)$ near this region of distinct layering. The surrounding area exhibits characteristics indicative of mechanically induced turbulence $(\mathrm{Ri}<$ 0.25). In fact, predominately small values of Ri persist throughout regions where turbulence was indicated in the echo power data shown in Fig. 7, as would be expected in measurements of the CBL.

To this point, we have shown how temporal filtering can be used to separate atmospheric features, such as precipitation and clear-air turbulence. In the next sec- 

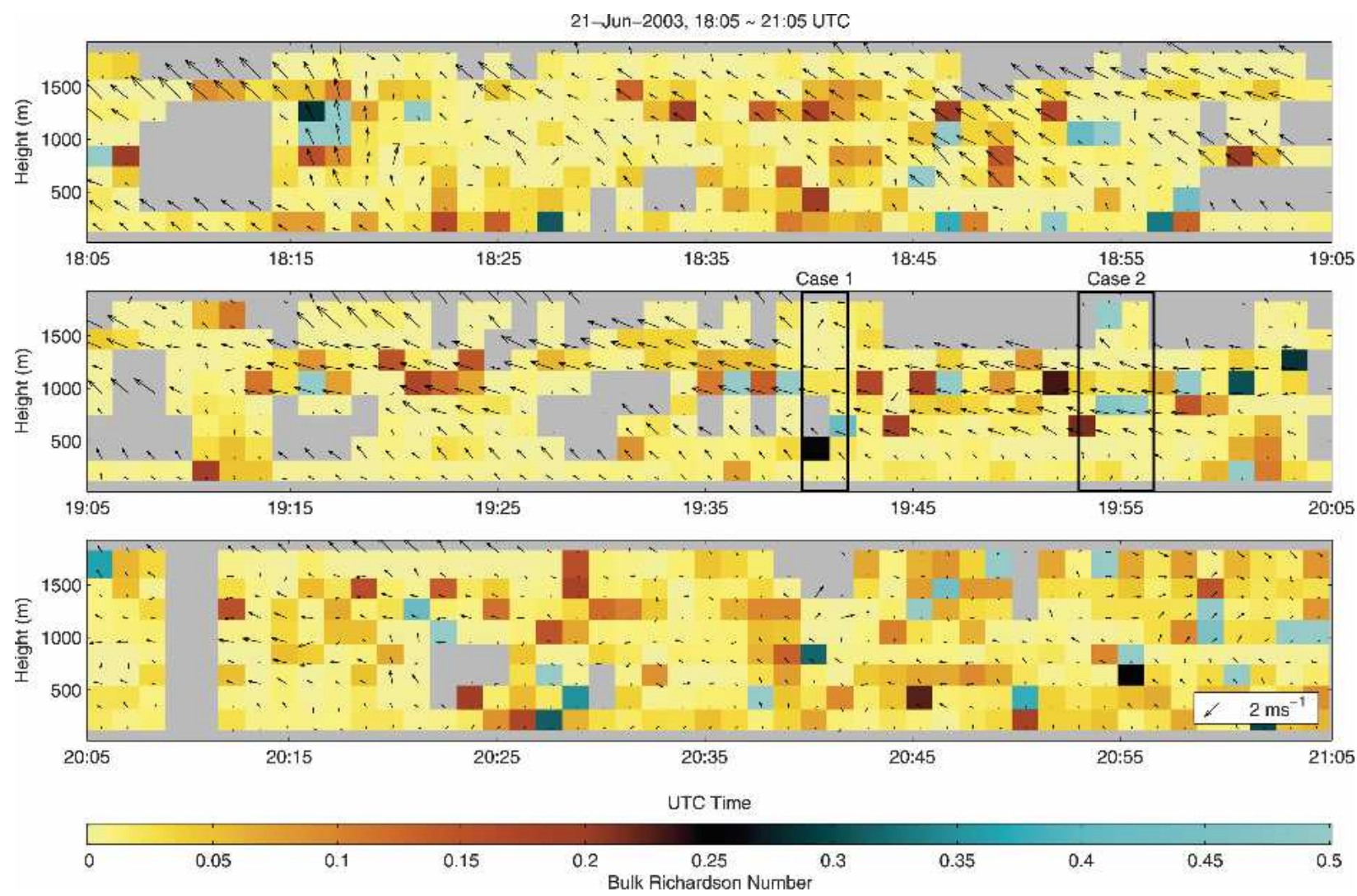

FIG. 9. Time history of Richardson number Ri calculated from the estimated TEP wind vectors and sounding data from Albany, NY. The altitude and temporal resolution of the Ri data are $200 \mathrm{~m}$ and $75 \mathrm{~s}$, respectively.

tion, this process is combined with imaging to study the small-scale variability of two specific precipitation events and how turbulence can affect these events.

\section{c. Small-scale variability and the interaction of precipitation and turbulence}

Data from two contrasting precipitation events are now presented. By temporally filtering and imaging the echo power in the three-dimensional conical volume above the radar, we provide examples of the effects of the wind field and clear-air turbulence on the formation of precipitation. As stated previously, clustering of rain can occur due to turbulent effects on coalescence and breakup (Pruppacher and Klett 1997; Jameson et al. 1999). It is further shown that vertical wind can affect the duration that the rain drops interact with the turbulent layers, thus affecting formation.

\section{1) Case 1: Turbulence-Induced COAlescence}

The data for the first case study were taken over the approximate 2.5-min period 1939:38-1942:02 UTC from the surface to the maximum altitude of $1.93 \mathrm{~km}$.
The region corresponding to case 1 is outlined in the previous time-history plots. As stated in section 3, the imaged region encompasses zenith angles within $12.5^{\circ}$, defining a conical volume above the radar (see Fig. 1). At the maximum altitude of $1.93 \mathrm{~km}$, the threedimensional volume has an approximate width of 856 $\mathrm{m}$. A sequence of separated isosurfaces for precipitation (blue) and clear-air turbulence (yellow) are shown in Fig. 10. The temporal evolution of the precipitation can be observed over these 15 frames. For presentation purposes, note that only every third frame is shown, providing a temporal resolution of approximately $10 \mathrm{~s}$. Nevertheless, both spatial and temporal continuity are present in these data. The first frame was chosen just before the precipitation was formed-at least particles of sufficient size and number to produce echo power higher than the isosurface level of $52.5 \mathrm{~dB}$. The first five frames (top row) show the descent of the rain pocket into the turbulent layer. Subsequently, the particles begin to interact with the turbulence, and the volume of the precipitation isosurface increases and begins to descend through the layer. It is likely that the mixing induced by the turbulent layer causes more efficient 

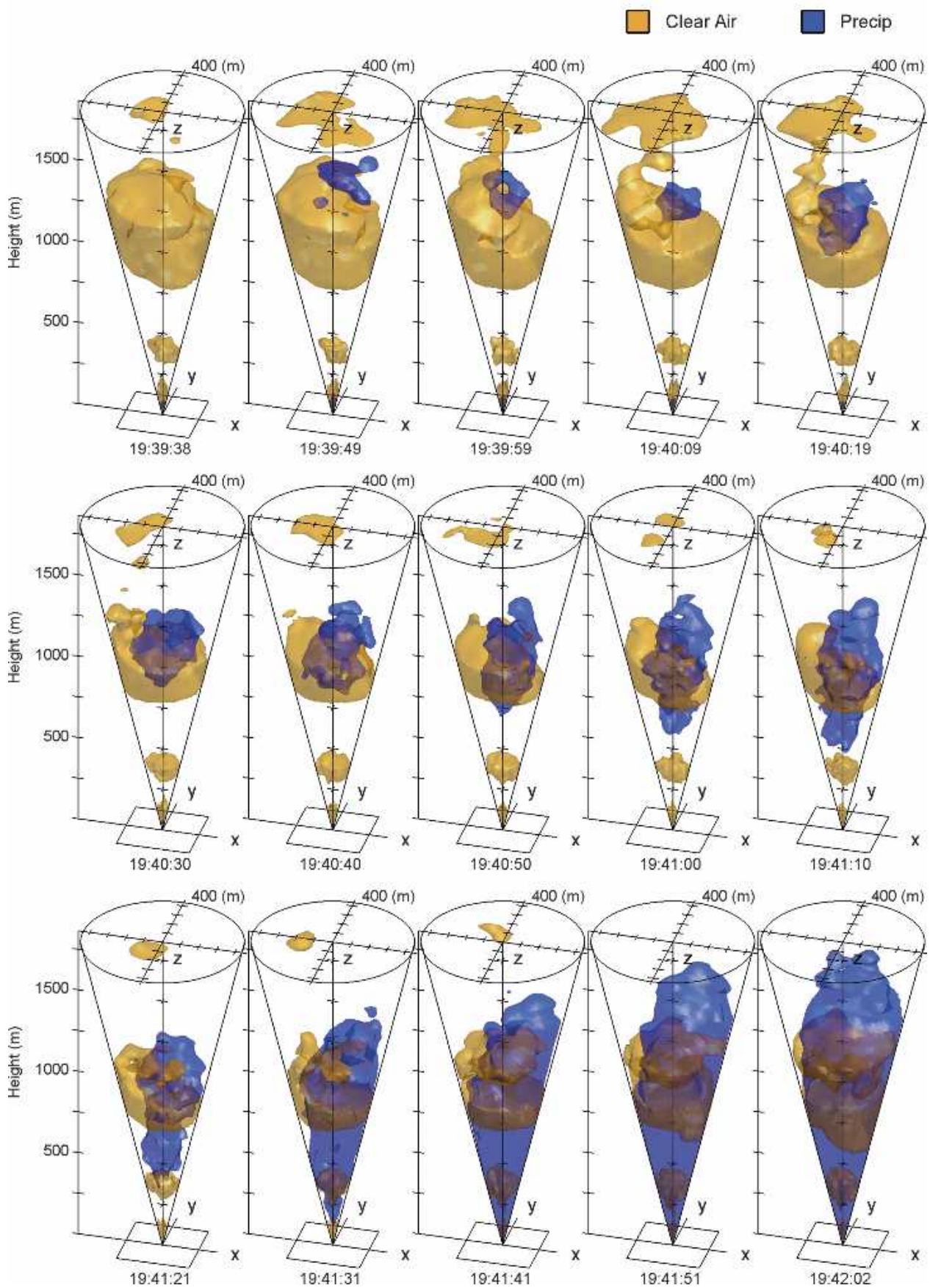

FIG. 10. A 2.5-min sequence of three-dimensional conical images of isolated precipitation (blue) and clear-air turbulent (yellow) echoes. The isosurfaces where obtained at power levels of $52.5 \mathrm{~dB}$ (precipitation) and $45.8 \mathrm{~dB}$ (clear air). At the maximum altitude of $1.93 \mathrm{~km}$, the horizontal extent of the conical volume is approximately $856 \mathrm{~m}$.

coalescence. This hypothesis is substantiated by the vertical velocity data shown in Fig. 4, which shows larger fall velocities below the turbulent layer. The final five frames (bottom row) show the conical volume be- coming filled with precipitation. However, the turbulent layers are still present and observable using our imaging procedure.

It should be emphasized that the levels of the isos- 
urfaces ( $52.5 \mathrm{~dB}$ for precipitation, $45.8 \mathrm{~dB}$ for clear air) were chosen to study the interaction of these two distinct signals. In the case of precipitation, it is possible that the volume was filled with relatively weak (less than $52.5 \mathrm{~dB}$ ) rain signals, but these are not shown given the chosen isosurface level. The flexibility of such an analysis technique is evident. For example, it would easily be possible to create a bank of bandpass temporal filters, each with separate three-dimensional images. The center velocities of the filters could be chosen to spatially isolate particles of different fall velocities as a proxy for drop size (Palmer et al. 1998). Recent work by Worthington (2004) showed three-dimensional imaging results similar to those of the present research but using VHF (6-m wavelength) data from the MU radar.

\section{2) CASe 2: Turbulence-Induced breakup}

The second case study was derived from data taken during the approximate 3.5-min period 1952:58-1956:33 UTC over the same altitude range as in case 1 . For these data, the temporal resolution was reduced to $15 \mathrm{~s}$ by presenting only every fourth frame, allowing study of the entire precipitation event with reasonable presentation quality. The sequence of three-dimensional isosurfaces for both precipitation and clear air is presented in Fig. 11. In the first five frames, an intense precipitation echo is seen to descend near the top of the turbulent layer at $1.2 \mathrm{~km}$. The descent continues in the next five frames, but as the precipitation begins to interact with the turbulent motion, the intensity of the echo diminishes. In the last five frames (bottom row) the precipitation isosurface dissipates, leaving only the clear-air turbulent echo. Why would the characteristics of this event differ from those of case 1? By examining the time history of the clear-air wind profiles in Fig. 8, a reason for the difference can be ascertained. For the time period corresponding to case 2 , a significant updraft $\left(0.5 \mathrm{~m} \mathrm{~s}^{-1}\right)$ is seen at 1955 UTC from the surface to approximately $500 \mathrm{~m}$. This is in contrast to case 1 , in which downward velocities dominated. It is likely that the upward velocities served to keep the raindrops aloft for a longer duration than would have been the case otherwise. This additional time allowed more interaction of the mixing processes of the turbulent layer, resulting in significant breakup of the larger drops. This hypothesis is strengthened by studying the tilt of the precipitation echoes in Fig. 6. At 1955 UTC and above $1.5 \mathrm{~km}$, the tilt is very steep, corresponding to large fall speeds, or large drops. Below the turbulent layer, the precipitation echo is only visible through our temporal filtering process but shows a shallower slope, indicative of small drops or drizzle. These smaller drops could be caused by turbulence-induced breakup. Of course, one should be aware that the tilt of the precipitation echo is affected by vertical motion, and any quantitative measure of drop size, for example, would need to take this into account.

Other possible effects of updrafts on precipitation have been noted by Kollias et al. (2001). In that work, the authors showed how upward motion in a convective storm could cause Doppler sorting, with larger drops concentrated toward the outer regions of the updraft. For our case of rather weak convective updrafts, however, it is unlikely that such a sorting mechanism was at play. Another possibility is that the updraft kept the raindrops aloft near a dry layer and evaporation caused the observed effect. Water vapor measurements with the necessary vertical resolution were not available to test this possibility. Nevertheless, evaporation should be mentioned as one potential mechanism to explain the observed characteristics.

The individual frames shown in Figs. 10 and 11 can be considered as instantaneous three-dimensional views of the structure within the transmit beam of the TEP radar. It should be emphasized, however, that many of the features seen in the time sequence of images could be explained by advection. Given a nonzero horizontal wind, it is possible that horizontal inhomogeneity could cause temporal variations in both the turbulent and precipitation fields. Future work will attempt to address this issue by studying the effects of averaging time. In essence, this will provide a mechanism to investigate Taylor's frozen turbulence hypothesis using the TEP radar.

\section{Conclusions}

An experiment was conducted in June 2003 using the 915-MHz TEP imaging radar in Amherst, Massachusetts, for the purpose of studying the interaction of precipitation and turbulence. The TEP radar is capable of high-resolution observations of the boundary layer by imaging a conical volume above the radar defined by the transmit beamwidth $\left( \pm 12.5^{\circ}\right)$. The spatial resolution was on the order of $30-40 \mathrm{~m}$ with a 5-s temporal resolution. During the experiment, sporadic liquid precipitation occurred that was detected by the radar along with simultaneous clear-air turbulence echoes.

Using the distinct radial velocity signatures of precipitation and clear-air turbulence, it was possible to use temporal filtering along with imaging to study their small-scale interaction. Two contrasting case studies were presented. In the first case, evidence was provided showing an enhancement in coalescence when relatively light rain passed through a turbulent layer. In addition, three-dimensional imaging results empha- 

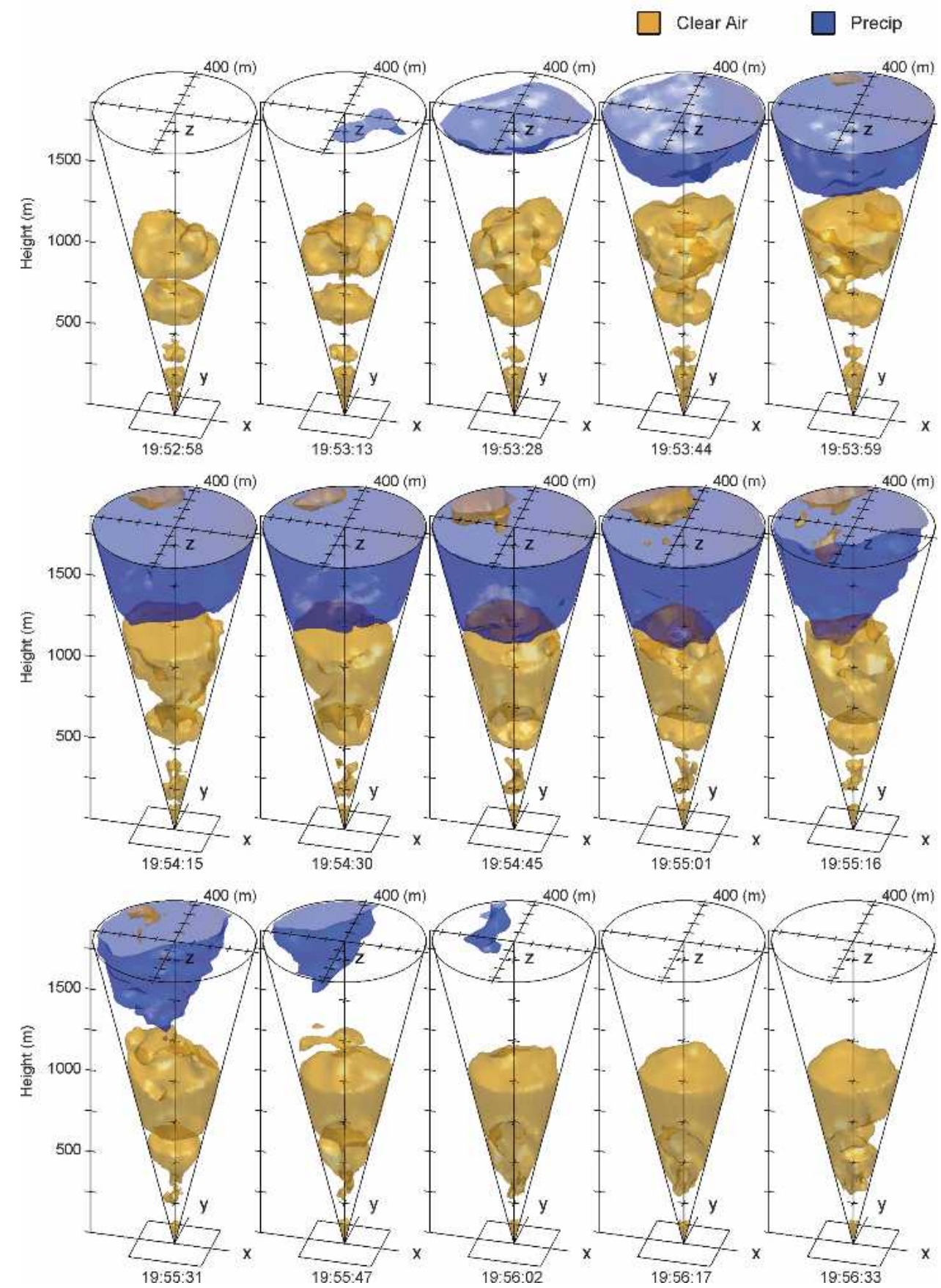

FIG. 11. Similar to the previous figure, except for a 3.5 -min sequence of a contrasting precipitation event. In this case, the intensity of the precipitation echo is seen to diminish as it progresses through the turbulent layer.

sized the horizontal and vertical inhomogeneity often seen in precipitation. A second case was presented where an intense rain echo was seen to dissipate as it came in close proximity to the turbulent layer. In contrast to the first case, a relatively strong updraft was observed by the radar below the altitude of the turbulent layer. Presumably, this updraft facilitated the breakup of larger drops, resulting in a much weaker radar echo below the layer.

In part, this work was conducted to show the atmo- 
spheric research community the power of imaging radar systems. With high spatial and temporal resolution, it is possible to have a three-dimensional, virtual reality view of both precipitation and turbulence in the boundary layer. The $915-\mathrm{MHz}$ TEP radar was developed by the University of Massachusetts in the 1990s (Mead et al. 1998) and is undoubtedly one of the most sophisticated boundary layer radars in use today.

Acknowledgments. RDP, BLC, and MWH were supported by the Army Research Office through Grant DDAD19-01-1-0407. SJF and FJL-D were supported by the Army Research Office (Atmospheric Sciences) through Grant DAAG55-98-1-0480. The authors thank V. Tellabati for his work on the calibration of the TEP array.

\section{REFERENCES}

Capon, J., 1969: High-resolution frequency-wavenumber spectrum analysis. Proc. IEEE, 57, 1408-1419.

Chau, J. L., and R. F. Woodman, 2001: Three-dimensional coherent radar imaging at Jicamarca: Comparison of different inversion techniques. J. Atmos. Sol.-Terr. Phys., 63, 253-261.

Cheong, B. L., M. W. Hoffman, R. D. Palmer, S. J. Frasier, and F. J. López-Dekker, 2004: Pulse pair beamforming and the effects of reflectivity field variations on imaging radars. $R a$ dio Sci., 39, RS3014, doi:10.1029/2002RS002843.

Chilson, P. B., C. W. Ulbrich, and M. F. Larsen, 1995: The effects of particle size distributions on cross-spectral phase measurements in spatial interferometry. Radio Sci., 30, 1065-1083.

Cohn, S. A., 1995: Radar measurements of turbulent eddy dissipation rate in the troposphere: A comparison of techniques. J. Atmos. Oceanic Technol., 12, 85-95.

— R. R. Rogers, S. Jascourt, W. L. Ecklund, D. A. Carter, and J. S. Wilson, 1995: Interactions between clear-air reflective layers and rain observed with a boundary layer wind profiler. Radio Sci., 30, 323-341.

Crane, R. K., 1990: Space-time structure of rain rate fields. $J$. Geophys. Res., 95, 2011-2020.

Ecklund, W. L., D. A. Carter, and B. B. Balsely, 1988: A UHF wind profiler for the boundary layer: Brief description and initial results. J. Atmos. Oceanic Technol., 5, 432-441.

Farley, D., H. Ierkic, and B. Fejer, 1981: Radar interferometry: A new technique for studying plasma turbulence in the ionosphere. J. Geophys. Res., 86, 1467-1472.

Fukao, S., T. Sato, T. Tsuda, S. Kato, K. Wakasugi, and T. Makihira, 1985a: The MU radar with an active phased array system, 1, Antenna and power amplifiers. Radio Sci., 20, 11551168.

- T. Tsuda, T. Sato, S. Kato, K. Wakasugi, and T. Makihira, 1985b: The MU radar with an active phased array system, 2 , In-house equipment. Radio Sci., 20, 1169-1176.

Gossard, E. E., 1990: Radar research on the atmospheric boundary layer. Radar in Meteorology, D. Atlas, Ed., Amer. Meteor. Soc., 477-527.

Gunn, R., and G. D. Kinzler, 1949: The terminal velocity of fall for water drops in stagnant air. J. Meteor., 15, 452-461.

Haykin, S., 1985: Array Signal Processing. Prentice-Hall, 433 pp. Hélal, D., M. Crochet, H. Luce, and E. Spano, 2001: Radar im- aging and high-resolution array processing applied to a classical VHF-ST profiler. J. Atmos. Sol.-Terr. Phys., 63, 263-274.

Hocking, W. K., 1986: Observation and measurement of turbulence in the middle atmosphere with a VHF radar. J. Atmos. Terr. Phys., 48, 655-670.

Hysell, D. L., 1996: Radar imaging of equatorial $F$ region irregularities with maximum entropy interferometry. Radio Sci., 31, 1567-1578.

Jain, A. R., Y. J. Rao, P. B. Rao, V. K. Anandan, S. H. Damle, P. Balamuralidhar, A. Kulkarni, and G. Viswanathan, 1995: Indian MST radar-Part II: First scientific results in ST mode. Radio Sci., 30, 1139.

Jameson, A. R., A. B. Kostinski, and A. Kruger, 1999: Fluctuation properties of precipitation. Part IV: Finescale clustering of drops in variable rain. J. Atmos. Sci., 56, 82-91.

Kollias, P., B. A. Albrecht, and J. F. D. Marks, 2001: Raindrop sorting induced by vertical drafts in convective clouds. Geophys. Res. Lett., 28, 2787-2790.

Kudeki, E., and R. Woodman, 1990: A poststatistics steering technique for MST radar applications. Radio Sci., 25, 591-594.

—_, and F. Sürücü, 1991: Radar interferometric imaging of fieldaligned plasma irregularities in the equatorial electrojet. Geophys. Res. Lett., 18, 41-44.

— , B. G. Fejer, D. T. Farley, and H. M. Ierkic, 1981: Interferometer studies of equatorial $F$ region irregularities and drifts. J. Geophys. Res., 8, 377-380.

Lopez-Dekker, P. L., and S. J. Frasier, 2004: Radio acoustic sounding with a UHF volume imaging radar. J. Atmos. Oceanic Technol., 21, 766-776.

Luce, H., M. Crochet, and F. Dalaudier, 2001: Temperature sheets and aspect sensitive radar echoes. Ann. Geophys., 19, 899920.

Mead, J. B., G. Hopcraft, S. J. Frasier, B. D. Pollard, C. D. Cherry, D. H. Schaubert, and R. E. McIntosh, 1998: A volume-imaging radar wind profiler for atmospheric boundary layer turbulence studies. J. Atmos. Oceanic Technol., 15, 849859.

Palmer, R. D., M. F. Larsen, E. L. Sheppard, S. Fukao, M. Yamamoto, T. Tsuda, and S. Kato, 1993: Poststatistic steering wind estimation in the troposphere and lower stratosphere. Radio Sci., 28, 261-271.

, S. Gopalam, T. Yu, and S. Fukao, 1998: Coherent radar imaging using Capon's method. Radio Sci., 33, 1585-1598.

Pfister, W., 1971: The wave-like nature of inhomogeneities in the E-region. J. Atmos. Terr. Phys., 33, 999-1025.

Pollard, B. D., S. Khanna, S. J. Frasier, J. C. Wyngaard, D. W. Thomson, and R. E. McIntosh, 2000: Local structure of the convective boundary layer from a volume-imaging radar. $J$. Atmos. Sci., 57, 2281-2296.

Pruppacher, H. R., and J. D. Klett, 1997: Microphysics of Clouds and Precipitation. 2d ed. Kluwer Academic Press, 954 pp.

Rao, P. B., A. R. Jain, P. Kishore, P. Balamuralidhar, S. H. Damle, and G. Viswanathan, 1995: Indian MST radar-Part I: System description and sample vector wind measurements in ST mode. Radio Sci., 30, 1125.

Röttger, J., and H. Ierkic, 1985: Postset beam steering and interferometer applications of VHF radars to study winds, waves, and turbulence in the lower and middle atmosphere. Radio Sci., 20, 1461-1480.

Tatarskii, V. I., 1961: Wave Propagation in a Turbulent Medium. McGraw-Hill, 285 pp.

Vaillancourt, P. A., and M. K. Yau, 2000: Review of particle- 
turbulence interactions and consequences for cloud physics. Bull. Amer. Meteor. Soc., 81, 285-298.

Wakasugi, K., A. Mizutani, M. Matsuo, S. Fukao, and S. Kato, 1986: A direct method for deriving drop-size distribution and vertical air velocities from VHF Doppler radar spectra. $J$. Atmos. Oceanic Technol., 3, 623-629.

Weber, B. L., and Coauthors, 1990: Preliminary evaluation of the first NOAA demonstration network wind profiler. J. Atmos. Oceanic Technol., 7, 909-918.

Woodman, R. F., 1971: Inclination of the geomagnetic field measured by an incoherent scatter technique. J. Geophys. Res., 76, 178-184.
_ 1997: Coherent radar imaging: Signal processing and statistical properties. Radio Sci., 32, 2373-2391.

- , and A. Guillen, 1974: Radar observations of wind and turbulence in the stratosphere and mesosphere. J. Atmos. Sci., 31, 493-505.

Worthington, R. M., 2004: All-weather volume imaging of the boundary layer and troposphere using the MU radar. Ann. Geophys., 22, 1407-1419.

Yu, T.-Y., R. D. Palmer, and D. L. Hysell, 2000: A simulation study of coherent radar imaging. Radio Sci., 35, 1129-1141. , _- and P. B. Chilson, 2001: An investigation of scattering mechanisms and dynamics in PMSE using coherent radar imaging. J. Atmos. Sol.-Terr. Phys., 63, 1797-1810. 